\title{
Kinetics of the EVD process for growing thin zirconia/yttria films on porous alumina substrates
}

\author{
H.W. BRINKMAN, G.Z. CAO, J. MEIJERINK, K.J. DE VRIES and A.J. BURGGRAAF \\ Laboratories of Inorganic Chemistry, Materials Science and Catalysis, Department of Chemical \\ Technology, University of Twente, P.O. Box 217, 7500 AE Enschede, The Netherlands
}

\begin{abstract}
The electrochemical vapour deposition (CVD/EVD) method has proven to be a good technique to form thin, gas tight dense solid electrolyte or mixed conducting films on porous substrates. Applications of the so formed systems are in solid oxide fuel cells (SOFC), oxygen sensors, oxygen separation membranes and electrocatalytic reactors.

In this paper, experimental results on the kinetics of the deposition by the EVD method of dense zirconia-yttria layers on porous $\alpha$-alumina substrates are presented, and compared with theoretical models. The experimental work concerns mainly the effect of temperature on the growth rate of the EVD film. At $1000^{\circ} \mathrm{C}$, layer growth occurs linear with time under current process conditions; in this case diffusion of the oxygen source reactant in the substrate pores is the rate limiting step for the EVD process. Between $900^{\circ} \mathrm{C}$ and $1000^{\circ} \mathrm{C}$ the growth rate limitation changes to the electrochemical transport through the film, which is parabolic with time. This behaviour is predicted by the theoretical model.
\end{abstract}

\section{Introduction}

The ElectroChemical Vapour Deposition (abbreviated as CVD/EVD) technique was originally developed by Westinghouse Electric Corporation (Pittsburg, USA) to form thin gas tight solid electrolyte (e.g. Yttria Stabilized Zirconia, YSZ) layers on porous substrates for Solid Oxide Fuel Cells (SOFC) [1]. More recent applications of CVD/EVD grown layers are the possible use in oxygen sensors, electrocatalytic reactors and as oxygen separation membranes. Especially in the last mentioned application, the thickness of the membrane layer is of importance: in the case that the bulk electrochemical diffusion of oxygen ions through the layer is the rate limiting step in the separation process, membrane layers should be as thin as possible to obtain a maximum oxygen permeation rate. By means of the CVD/EVD method, gas tight layers with thicknesses as small as $0.2-0.5 \mu \mathrm{m}$ can be obtained [2].

The principles of the CVD/EVD technique have been outlined extensively in the literature [1,3- 
5]. A mixture of metal chlorides $\left(\mathrm{ZrCl}_{4}\right.$ and $\left.\mathrm{YCl}_{3}\right)$ is separated from an oxygen source reactant (water vapour, oxygen or a mixture) by a porous ceramic substrate. In the beginning, the reactants diffuse into the substrate pores and react to form a metal oxide (zirconia-yttria solid solution, ZY) which deposits on the pore wall. When this process proceeds, pore narrowing occurs until at a certain moment the pores become totally plugged with the metal oxide. The formentioned stages are together known as the (modified) CVD stage. Layer or film growth in the subsequent EVD stage is only possible in metal oxides with mixed (i.e. ionic and electronic) conducting behaviour. The oxygen source reactant is reduced at the oxygen source/film interface; oxygen ions (counterbalanced by electrons) migrate through the growing film to the film/metal chloride interface, where they react at this interface with the metal chlorides to form (again) the metal oxide.

In the past few years several groups have investigated the kinetics of the EVD process for growing zirconia/yttria layers on porous substrates [1,5-9]. Among others, Carolan \& Michaels [7] and Pal \& Singhal [6] have found that the EVD process obeys a parabolic law, in which the film thickness is proportional to the square root of the deposition time. On the other hand, for example Isenberg [1] showed that the deposited film thickness was a linear function of time. To investigate this discrepancy, Lin et al. [9] have developed a model incorporating oxygen/water diffusion through the substrate pores, reduction reaction at the oxygen source/film interface, bulk electrochemical transport in the film, and oxidation reaction at the film/metal chloride interface. This model showed that there is always a transition behaviour for any EVD process on porous substrates. In the beginning of the EVD phase, diffusion of the oxygen source reactant through the substrate pores is the rate limiting step for layer growth. When the deposition time (or layer thickness) is larger than the so-called transition time (or thickness), the film bulk diffusion turns to play the dominant role in the film growing process $[9,10]$.

The experimental work Lin [9] has performed in our laboratories was focused on the effects of oxygen partial pressure and substrate pore dimensions on the EVD film growth rate. The experimental results showed that the substrate pore diffusion was the rate limiting step for (linear) layer growth in the first $\sim 5$ hours for $\alpha$-alumina substrates at $1000^{\circ} \mathrm{C}$ and a total pressure of 2 mbar. The transition time for the investigated EVD process was too long to observe the parabolic law within the experimental deposition period [9].

Another way to show the transition behaviour in the EVD process is to investigate the influence of the deposition temperature on the film growth rate, at further the same process conditions. Results of this investigation are presented here. In the coming part of this paper, the experimental setup is described, after which the results are presented. These results are analyzed and compared with the theoretical model developed earlier [9].

\section{Experimental}

All experiments were performed in a home built CVD/EVD reactor, called the MM1 reactor. A schematic view of the central part of this reactor is given in Figure 1. An extensive description of this reactor is given in [5]. A porous $\alpha$-alumina substrate (characterized in Table I) was mounted onto

Table I: Characteristics of $\alpha$-alumina substrates used in the CVD/EVD experiments

\begin{tabular}{|lc|}
\hline Diameter & $12 \mathrm{~mm}$ \\
Thickness & $2 \mathrm{~mm}$ \\
Mean pore diameter & $0.16 \mu \mathrm{m}$ \\
Porosity & $50 \%$ \\
\hline
\end{tabular}




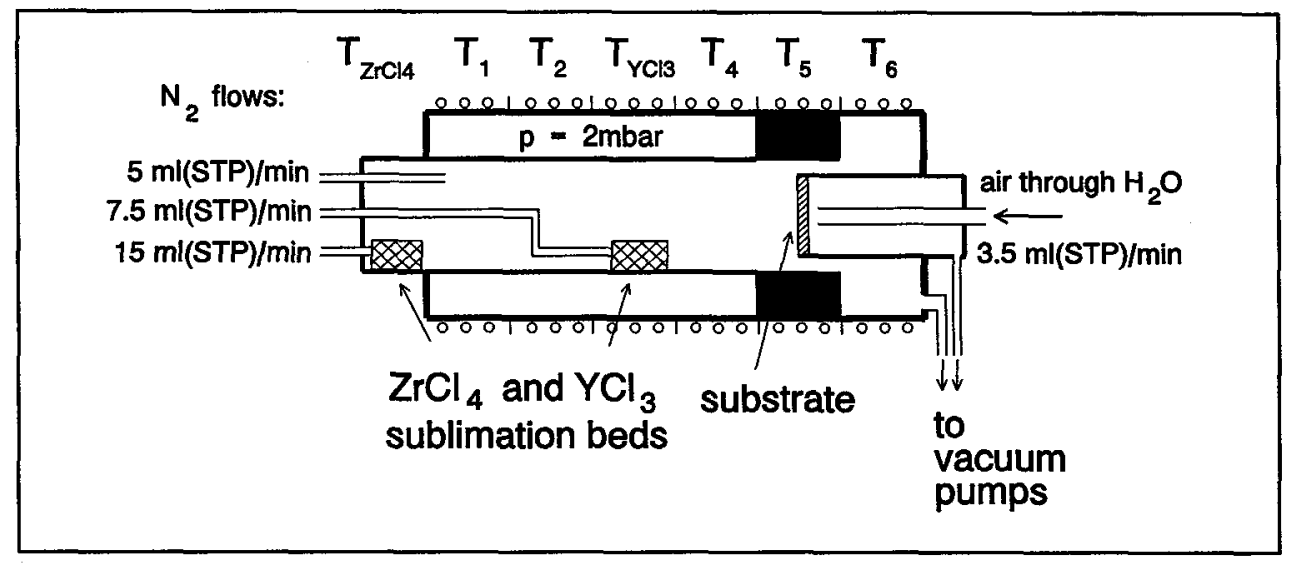

Figure 1: Schematic view of the central part of the MM1 reactor

the end of a dense alumina tube, separating the reactor into two chambers. The temperature inside the reactor was controlled by a six-zone furnace and some additional heating elements. Before an experiment was started, the zones were heated to their desired temperatures. About half an hour before the experiment started, the sublimation beds were filled with fresh $\mathrm{ZrCl}_{4}$ and $\mathrm{YCl}_{3}$ powder, and the beds were placed at the correct position in the reactor (see Figure 1). First, one hour deposition was performed at which the substrate temperature was $800^{\circ} \mathrm{C}$. All other process conditions are shown in Table II and Figure 1. The reason for performing CVD/EVD for one hour at $800^{\circ} \mathrm{C}$ for all samples was to keep the influence of the CVD part on the layer growth the same; always the same pore closure time is then established (around 40 minutes, see e.g. [2]). Then the temperature was kept at $800^{\circ} \mathrm{C}$ or raised to 900 or $1000^{\circ} \mathrm{C}$, and deposition continued for a desired period of time (1.5, 3 or 4 hours). The process conditions for these stages are shown in Table II.

By means of a Scanning Electron Microscope (Jeol JSM-35CF) connected with a Kevex Deltaclass EDX analyzer for Energy Dispersive X-ray analysis the thickness of the EVD grown layers was estimated. The real thickness was found by the Back-scattered Electron Image (BEI) and the formed phases (elements) were checked by EDX.

Table II: Overview of the process conditions of the CVD/EVD experiments (temperature zones of the furnace around the MM1 reactor are shown in Figure 1)

\begin{tabular}{|c|c|c|}
\hline $\begin{array}{l}\text { Metal chloride source temperatures: } \\
\mathrm{T}_{\mathrm{ZrCl} 4}=150^{\circ} \mathrm{C} \\
\mathrm{T}_{\mathrm{YCl} 3}=625^{\circ} \mathrm{C}\end{array}$ & $\begin{array}{l}\text { as } \mathrm{T}_{5}=800^{\circ} \mathrm{C} \text { then } \\
\text { as } \mathrm{T}_{5}=900^{\circ} \mathrm{C} \text { then } \\
\text { as } \mathrm{T}_{5}=1000^{\circ} \mathrm{C} \text { then }\end{array}$ & $\begin{aligned} \mathrm{T}_{4} & =700^{\circ} \mathrm{C} \\
\mathrm{T}_{6} & =600^{\circ} \mathrm{C} \\
\mathrm{T}_{4} & =750^{\circ} \mathrm{C} \\
\mathrm{T}_{6} & =650^{\circ} \mathrm{C} \\
\mathrm{T}_{4} & =800^{\circ} \mathrm{C} \\
\mathrm{T}_{6} & =650^{\circ} \mathrm{C}\end{aligned}$ \\
\hline
\end{tabular}




\section{Results}

For all substrates, zirconia/yttria layer growth occurred at the substrate side directed towards the chloride chamber. XRD anaiysis showed that the formed layers consisted mostly of the cubic YSZ phase, but also some monoclinic and tetragonal phases were observed. The layer thickness as a function of total deposition time (so including one hour deposition at $800^{\circ} \mathrm{C}$ ) for different deposition temperatures is shown in Figure 2. In most cases the layer thickness can be estimated rather good, although there is on average an inaccuracy of about 1-2 $\mu \mathrm{m}$ for each measurement (see Figure 2). As can be observed from the figure a straight line can be drawn through the measuring points at all three temperatures. The so observed linear layer growth rates are :

$$
\begin{aligned}
& \text { at } 1000^{\circ} \mathrm{C}: 1.6 \mu \mathrm{m} / \mathrm{h} \\
& \text { at } 900^{\circ} \mathrm{C}: 0.4 \mu \mathrm{m} / \mathrm{h} \\
& \text { at } 800^{\circ} \mathrm{C}: \quad 0 \mu \mathrm{m} / \mathrm{h} \text { (no observable layer growth). }
\end{aligned}
$$

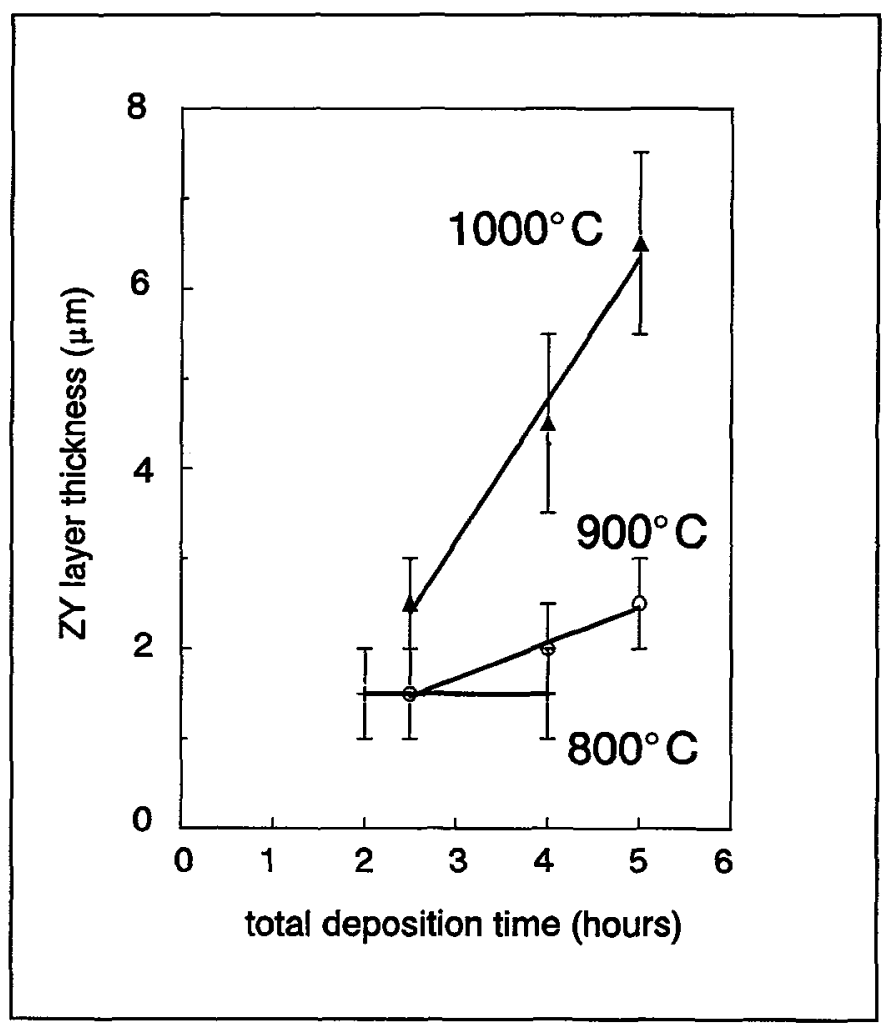

Figure 2: $\quad$ ZY layer thickness as function of total deposition time

\section{Analysis of the results and discussion}

In the first place it must be stated that the errors in the measurements are relatively large (see error bars in Figure 2), up to several tens of procents. Although at $1000^{\circ} \mathrm{C}$ a linear relation for the layer growth is very probable, at lower temperatures other relations between the layer thickness and the total 
deposition time will also hold within the measurement errors.

The above mentioned linear layer growth rates are obtained from the slope of the layer thickness vs. the total deposition time. This total deposition time consists of a CVD part (until the so called pore closure time) and an EVD part. With these experiments there is no use in extrapolating these lines to a layer thickness of zero and so estimating the pore closure time, since a quantitative value of the pore closure time has no meaning here. Compared with previous results the values for the layer growth rate obtained here are almost equal to the earlier reported ones. In previous papers $[5,9]$ it was found that the layer growth rate at $1000^{\circ} \mathrm{C}$ was about $1.5 \mu \mathrm{m} / \mathrm{h}$; the value of $1.6 \mu \mathrm{m} / \mathrm{h}$ is within the current measuring error.

The rate limiting step for the layer growth process will be evaluated in a similar way as is done before in our group [9,10], where is suggested that one may calculate the film growth rate for each of the steps assuming it is rate limiting. In the first place the surface exchange reactions are excluded; arguments for this exclusion were already given in previous papers [5,9]. When the diffusion of water through the pores is the rate limiting step, de following equation can be used for theoretically predicting the layer growth rate $\mathrm{dH} / \mathrm{dt}$, assuming that the oxygen partial pressure in the chloride chamber is negligible compared to the oxygen partial pressure in the water chamber (see e.g. [9]):

$$
\frac{d H}{d t}=\frac{V_{m} D_{w} P_{w, w c}}{2 L R T}
$$

When the bulk electrochemical transport in the EVD film is the rate limiting step, the following relation is used (see e.g. [9]):

$$
\frac{d H}{d t}=\frac{V_{m} R T}{4 F^{2} H}\left(\sigma_{p}^{o}\left(\left[P_{o(w)}\right]^{1 / 4}-\left[P_{o(m)}\right]^{1 / 4}\right)+\sigma_{n}^{0}\left(\left[P_{o(m)}\right]^{-1 / 4}-\left[P_{o(w)}\right]^{-1 / 4}\right)\right)
$$

The values that are used in equations (1) and (2) are shown in Table III. With these parameters, equations (1) and (2) can be written in the following temperature dependent forms (temperature $\mathrm{T}$ in Kelvin):

pore diffusion:

$$
\frac{d H}{d t}=\frac{82}{\sqrt{T}}(\mu \mathrm{m} / \mathrm{h})
$$

bulk electrochemical diffusion:

$$
\frac{\mathrm{dH}}{\mathrm{dt}}=6.8 \cdot 10^{4} \mathrm{Te}^{-19379 / \mathrm{T}}+3.8 \cdot 10^{14} \mathrm{Te}^{-45024 / \mathrm{T}}(\mu \mathrm{m} / \mathrm{h})
$$

The theoretical layer growth rates are given as a function of temperature in Figure 3 (solid lines). The accuracy obtained in this figure is relative low, since some parameters are not known with sufficient accuracy; especially $\mathrm{P}_{\mathrm{o}(\mathrm{m})}$ which may have a value between $10^{-15}$ and $10^{-23} \mathrm{~atm}$. The forms of the curves, however, are correct. From this figure it follows that the theoretical transition temperature (from pore diffusion as rate limiting step to electrochemical diffusion as rate limiting step) is around $825^{\circ} \mathrm{C}$ $(1100 \mathrm{~K})$.

At $1000^{\circ} \mathrm{C}$, it is very probable that the diffusion of the water/air mixture through the substrate pores is the rate limiting step for EVD film growth. This is confirmed by two arguments: the layer thickness can be very well related to the total deposition time by a straight line, and the order of magnitude for the layer growth rate is well comparable: experimentally $1.6 \mu \mathrm{m} / \mathrm{h}$, theoretically around $2.5 \mu \mathrm{m} / \mathrm{h}$ when pore diffusion is rate limiting. According to the experimental results (Figure 2), the 
Table III: Values for parameters used in equations (1) and (2)

\begin{tabular}{|c|c|c|c|}
\hline symbol & description & value & dimension \\
\hline $\mathrm{V}_{\mathrm{m}}$ & average molar volume of YSZ & $20.7 \cdot 10^{-6}$ & $\mathrm{~m}^{3} \cdot \mathrm{mol}^{-1}$ \\
\hline $\mathrm{D}_{\mathrm{w}}$ & $\begin{array}{l}\text { effective water diffusion coefficient } \\
\qquad\left(\varepsilon=0.5, \mu_{\mathrm{k}}=0.4\right)\end{array}$ & $3.66 \cdot 10^{-2} \sqrt{ } \mathrm{T}$ & $\mathrm{m}^{2} \cdot \mathrm{s}^{-1}$ \\
\hline $\mathrm{L}$ & thickness of the substrate & $2 \cdot 10^{-3}$ & $\mathrm{~m}$ \\
\hline $\mathbf{R}$ & gas constant & 8.3143 & $\mathrm{~J} \cdot \mathrm{mol}^{-1} \cdot \mathrm{K}^{-1}$ \\
\hline$P_{w, w c}$ & water partial pressure in water chamber & 100 & $\mathrm{~Pa}$ \\
\hline$P_{o(w)}$ & oxygen partial pressure in water chamber & $\sim 10^{-3}$ & atm \\
\hline$P_{o(m)}$ & oxygen partial pressure in chloride chamber & $\sim 10^{-17}$ & atm \\
\hline$\sigma_{\mathrm{p}}^{0}$ & $\begin{array}{l}\text { hole conductivity of } \mathrm{ZrO}_{2}-8 \mathrm{~m} \% \mathrm{Y}_{2} \mathrm{O}_{3} \\
\text { at } \mathrm{P}_{\mathrm{O}_{2}}=1 \mathrm{~atm}[11]\end{array}$ & $2.3 \cdot 10^{4} \mathrm{e}^{-1.67 \mathrm{eV} / \mathrm{kT}}$ & $\Omega^{-1} \mathrm{~m}^{-1} \mathrm{~atm}^{-1 / 4}$ \\
\hline$\sigma_{\mathrm{n}}^{0}$ & $\begin{array}{l}\text { electron conductivity of } \mathrm{ZrO}_{2}-8 \mathrm{~m} \% \mathrm{Y}_{2} \mathrm{O}_{3} \\
\text { at } \mathrm{P}_{\mathrm{O}_{2}}=1 \mathrm{~atm}[11]\end{array}$ & $1.3 \cdot 10^{9} \mathrm{e}^{-3.88 \mathrm{eV} / \mathrm{kT}}$ & $\Omega^{-1} \mathrm{~m}^{-1} \mathrm{~atm}^{1 / 4}$ \\
\hline $\mathrm{F}$ & Faraday constant & 96487 & $\mathrm{C} \cdot \mathrm{mol}^{-1}$ \\
\hline $\mathrm{H}$ & average value for EVD film thickness in eq. (2) & $1 \cdot 10^{-6}$ & $\mathrm{~m}$ \\
\hline
\end{tabular}

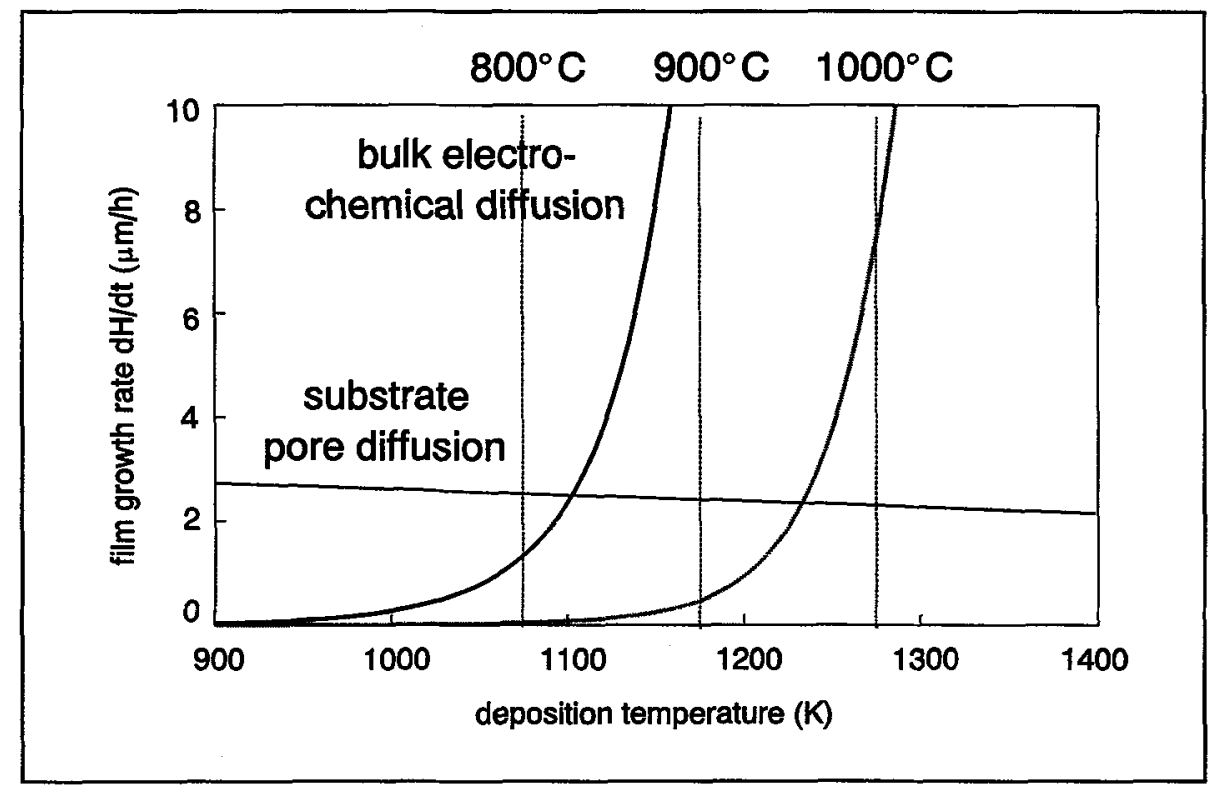

Figure 3: Theoretical EVD film growth rate as function of temperature (solid curves: parameters as in Table III; dotted curve: theory corresponding to experiments)

transition temperature is somewhat above $900^{\circ} \mathrm{C}$, since the low value of the layer growth rate $(0.4 \mu \mathrm{m})$ can not be caused by the fact that pore diffusion is rate limiting. When at $900^{\circ} \mathrm{C}$ the pore diffusion should be rate limiting, the layer growth rate should be larger, around $2-2.5 \mu \mathrm{m} / \mathrm{h}$ and not much deviating from the layer growth rate at $1000^{\circ} \mathrm{C}$. So at $900^{\circ} \mathrm{C}$ the bulk electrochemical diffusion through 
the $\mathrm{ZY}$ layer is most probably the rate limiting step. This is also the case at lower temperatures, e.g. $800^{\circ} \mathrm{C}$.

At $800^{\circ} \mathrm{C}$ a quantitative discrepancy exists between theory and experiment: by theory a layer growth rate (bulk diffusion limiting) of about $1 \mu \mathrm{m} / \mathrm{h}$ is found, while experimentally the layer growth rate should not be larger than several tenths of a $\mu \mathrm{m}$ (see Figure 2). Also at $900^{\circ} \mathrm{C}$ a discrepancy exists; according to theory, pore diffusion is the rate limiting step, while according to the experiments bulk diffusion is rate limiting. At this moment it is not yet clear what is the reason behind this discrepancy. The theory (solid lines in Figure 3) corresponds more to the experiments (Figure 2) when the curve for bulk diffusion is shifted somewhat to the right. This is shown by the dotted curve in Figure 3 . Then the transition temperature should be higher (between 900 and $1000^{\circ} \mathrm{C}$ ) and the layer growth at $800^{\circ} \mathrm{C}$ should be very low (up to several tenths of a $\mu \mathrm{m}$ ). This shift towards the right can only occur if some of the parameters in equation (2) have different values than those shown in Table III. One possibility is that $\mathrm{P}_{\mathrm{o}(\mathrm{m})}$, the oxygen partial pressure in the chloride chamber is higher than $10^{-17} \mathrm{~atm}$. But for a considerable shift to the right, a high $P_{o(m)}$ is necessary (only a few orders lower than $P_{o(w)}$ ). It is not likely, however, that the oxygen partial pressure in the chloride chamber is that high. Another possibility is that the shift to the right may correspond to somewhat lower effective values for $\sigma_{\mathrm{p}}{ }^{\circ}$ and $\sigma_{n}{ }^{\circ}$ than is mentioned in [11]. This may be due to the fact that the formed EVD layers were not totally cubic but also consisted of the monoclinic and tetragonal ZY phases. The effective values of $\sigma_{\mathrm{p}}^{\circ}$ and $\sigma_{\mathrm{n}}{ }^{\circ}$ were then lower because the relative amount of cubic YSZ was smaller than unity (as is the fact in [11]).

\section{Conclusions}

New experimental results, compared with theoretical analysis show that at $1000^{\circ} \mathrm{C}$, the growth rate of $Z Y$ layers on $\alpha$-alumina seems to be linear due to pore diffusion limitation. Between 900 and $1000^{\circ} \mathrm{C}$ a transition occurs to the bulk electrochemical diffusion as rate limiting step. Below $900^{\circ} \mathrm{C}$, the bulk electrochemical diffusion of oxygen through the EVD layer is the rate limiting step.

The experiments can be well compared with the theory in a qualitative way. However, comparison in a quantitative way may be somewhat difficult; this may be due to the fact that the effective conductivity values for bulk YSZ can be somewhat different than the values for thin films which consist, besides cubic, also of monoclinic and tetragonal phases.

\section{References}

[1] Isenberg, A.O., "Growth of refractory oxides layers by electrochemical vapor deposition (EVD) at elevated temperatures", in Proc. Symp. Electrode Materials, Processes for Energy Conversion and Storage, eds. J.D.E. McIntyre, S. Srinivasan and F.G. Will, The Electrochem. Soc. Inc., Princeton, NJ, 77-6 (1977) 572-583

[2] Lin, Y.S., de Vries, K.J., Brinkman, H.W. and Burggraaf, A.J., "Oxygen semipermeable solid oxide membrane composites prepared by electrochemical vapor deposition", J. Membr. Sci. 66 (1992) 211-226

[3] Dietrich, G. and Schäfer, W., "Advances in the development of thin-film cells for high temperature electrolysis", Int. J. Hydrogen Energy 9 (1984) 747-752

[4] Carolan, M.F. and Michaels, J.N., 1987, "Chemical vapour deposition of yttria-stabilized zirconia on porous substrates", Solid State Ionics 25 (1987) 207-216

[5] de Haart, L.G.J., Lin, Y.S., de Vries, K.J. and Burggraaf, A.J., "Modified CVD of nanoscale 
structures in and EVD of thin layers on porous ceramic membranes", J. Eur. Ceram. Soc. 8 (1991) $59-70$

[6] Pal, U.N. and Singhal, S.C., "Electrochemical vapor deposition of yttria-stabilized zirconia films", J. Electrochem. Soc. 137 (1990) 2937-2941

[7] Carolan, M.F. and Michaels, J.N., "Growth rates and mechanism of electrochemical vapor deposited yttria-stabilized zirconia films", Solid State Ionics 37 (1990) 189-195

[8] Schoonman, J., Dekker, J.P., Broen, J.W. and Kiwiet, N.J., "Electrochemical vapor deposition of stabilized zirconia and interconnection materials for solid oxide fuel cells", Solid State Ionics 46 (1991) 299-308

[9] Lin, Y.S., de Haart, L.G.J., de Vries, K.J. and Burggraaf, A.J., "A kinetic study of the electrochemical vapor deposition of solid oxide electrolyte films on porous substrates", $J$. Electrochem. Soc. 137 (1990) 3960-3966

[10] de Haart, L.G.J., Lin, Y.S., de Vries, K.J. and Burggraaf, A.J., "On the kinetic study of electrochemical vapour deposition", Solid State Ionics 47 (1991) 331-336

[11] Park, J.H. and Blumenthal, R.N., "Electronic transport in 8 mole percent $\mathrm{Y}_{2} \mathrm{O}_{3}-\mathrm{ZrO}_{2}$ ", J. Electrochem. Soc. 136 (1982) 2867-2876 